\title{
Empirical Study of China Stock Market and Economic Growth Based on VAR Model
}

\author{
Wu Yudong \\ School of Basic Science, Harbin University of Commerce, Harbin \\ wuyudong@aliyun.com
}

\begin{abstract}
China stock market has been making great contributions to China's economy since established. In this paper, a VAR model, with stock market factors and economic growth factors involved, is established to study the relation between China stock market and economic growth. The result indicates that a one-way Granger causality exists between the development scale of stock market and the animation of stock market, that is to say, a well developed and animate stock market will push forward economic development; and that the capitalization rate of stocks and the commercial value rate may promote each other, namely the better the development of stock market is, the higher the stock price is, hence increase of the value of stock. As a result, the healthy development of China economy will be facilitated.
\end{abstract}

Keywords: Stock market; Economic growth; VAR model

\section{Introduction}

After over two decades of development, China stock market has cultivated many Chinese investors, although in an unsteady manner. Stock market price, in accordance with the general rules of macro economy, is usually referred to as a "barometer" to the national economy, indicating the economic trends of a state. Therefore, the study of the interaction between China stock market and China economy may be of some practical significance.

Traditional economic measurement method is a model that describes variable relation on the basis of economic theory. However, economic theory can seldom be able to give a strict description to the dynamic association among different variables; besides, endogenous variable may appear in either side of the equation, which will complicate the evaluation and deduction. In response, a vector auto regression (VAR) model was born.

\section{Empirical Analysis of China Stock Market and Economic Growth}

\subsection{Correlation Analysis of China Stock Market and Economic Growth}

China's economy varies according to different development stages. It may be affected by many factors, such as season, geographic position and cultural environment. Quarterly gross domestic production (GDP) and stock trading market will be adopted for the price comparison. As shown in Fig. 1, the amount of stock transaction refers to the amount agreed on by both the buying and the selling parties according to relevant transaction rules when buying (selling) the stocks. Its correlation analysis with economic growth is shown in Fig. 2 below. 


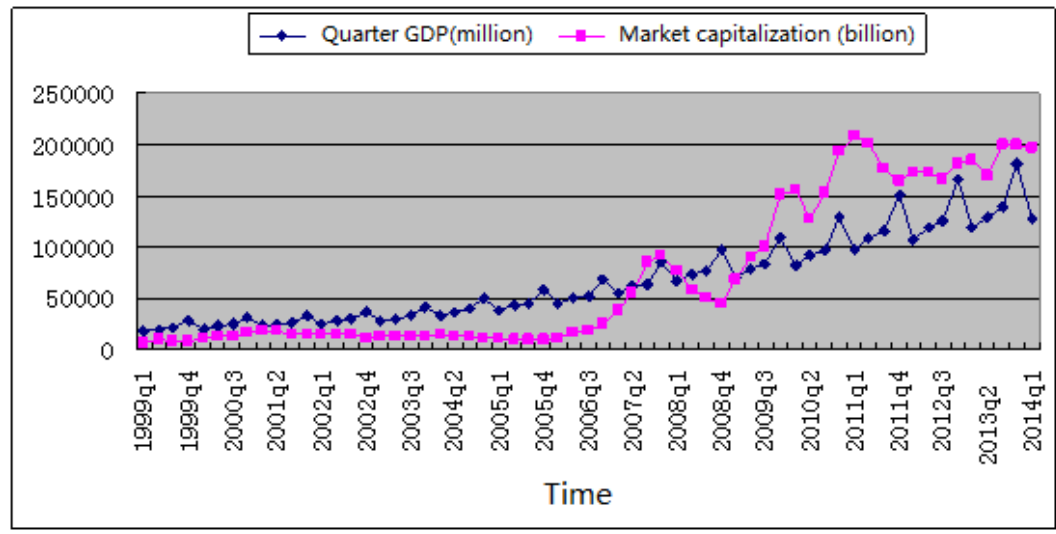

Figure 1. Quarterly GDP and Stock Circulation Market Value

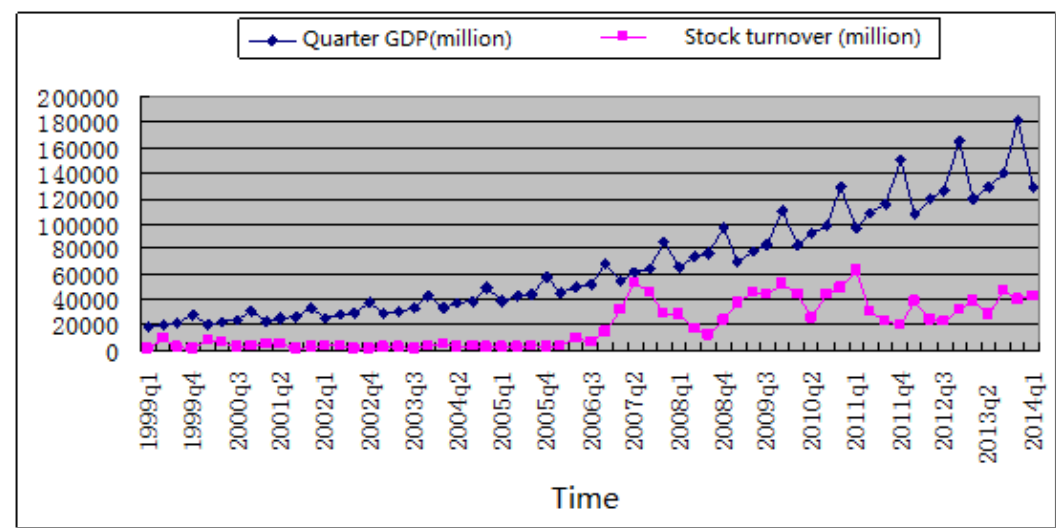

Figure 2. Quarterly GDP and Amount of Stock Transactions

Fig. 1 and Fig. 2 indicate a significant impact of season on economic growth, but the general trend is ascending. The years of 2006 to 2007 witnessed a rapid increase in the amount of stock transactions and stock circulation market value, which should mainly be attributed to the bull market of China stock market. Accounting from 2007 till today, a record low point appeared in 2008, negatively affected by the international financial crisis. At that time, China stock market was seriously impacted and entered a sluggish period. Yet after 2008, another peak showed itself and indicated the start of the function of China's 4 trillion yuan to stimulate its economy. Then the economy showed a more favorable trend. An ascending trend appeared in GDP, stock circulation market value and amount of stock transactions. But it did not last long. Till today, the amount of stock transactions has been fluctuating all the time since 2009 .

\subsection{Selection of Model Indicator}

Here are the major quarterly variables adopted in the establishment of VAR model: quarterly GDP, which is an optimum indicator to measure the economic condition of a state, reflects wealth and national strength, but does not show the economic development condition of the state, referred to as G; stock circulation market value, which means the total stock circulation market value (number of tradable circulation stock multiplied by the then stock price) in a certain period of time, referred to as L; the amount of stock transactions, which means the amount agreed upon by both the buying and the selling parties according to relevant transaction rules in the transaction of the stocks, referred to 
as $\mathbf{J}$ in the model; capitalization rate, which means the ratio of stock circulation market value against quarterly GDP, referred as $\mathrm{K}$ in the model; commercial value rate, which means the ratio of total amount of stock transactions against quarterly GDP, referred to as $\mathrm{T}$ in the model; turnover rate, which means the ratio of total amount of stock transactions against total circulation market value, referred to as $\mathrm{H}$. Economic growth rate means the constant increase of the output per capita (or per capita income) of a state, referred to as Y.

The data used in the paper is the quarterly data of from the first quarter of 1999 to the first quarter of 2014. It comes from two major aspects: economic growth-related data mainly comes from China Statistical Yearbook, and stock market-related data mainly comes from China Securities Regulatory Commission.

Trend term may be caused by the seasonal influences in the quarterly data. In response, the collected quarterly data is processed to eliminate the trend term. In this paper, X, an 11 quarterly adjustment, is adopted to realize detrending of variables, and at the same time, logarithmetics treatment is conducted on the data, thus removing the possibility of heteroscedasticity in time sequence. The variables after adjustment are expressed as: LKSA for quarterly capitalization, LTSA for quarterly commercial value rate, LYSA for quarterly economic growth rate, and LHSA quarterly turnover rate.

\subsection{Build up the Model}

2.3.1. Stationary Test of Variables: The steadiness of the quarterly data of the four variables is tested by Eviews6.0. The result is shown in Table 1:

Table 1. ADF Test Result

\begin{tabular}{cccccc}
\hline Variable name & $\begin{array}{c}\text { ADF statistical } \\
\text { magnitude }\end{array}$ & $\begin{array}{c}1 \% \text { critical } \\
\text { value }\end{array}$ & $\begin{array}{c}5 \% \text { critical } \\
\text { value }\end{array}$ & $\begin{array}{c}10 \% \text { critical } \\
\text { value }\end{array}$ & Conclusion \\
\hline LYSA & -6.51979 & -3.54406 & -2.91086 & -2.59309 & steady \\
LKSA & -1.35971 & -3.5461 & -2.91173 & -2.59355 & variable \\
LTSA & -2.77976 & -3.54406 & -2.91086 & -2.59309 & variable \\
LHSA & -3.45812 & -3.54406 & -2.91086 & -2.59309 & steady \\
I(LKSA) & -5.1965 & -3.5461 & -2.91173 & -2.59355 & steady \\
I(LTSA) & -10.0755 & -3.5461 & -2.91173 & -2.59355 & steady \\
\hline
\end{tabular}

In observing the test result of quarterly data, we can see that on $95 \%$ confidence level, the variable LYSA and variable LHSA have both been steady, but variable LKSA and variable LTSA have not. Therefore first difference should still be used on the latter two variables. Then we find that both of their first differences are steady on 95\% confidence level, which indicates that these two variables are first order co-integration and meet the requirements of co-integration test.

2.3.2. Co-integration Test: Previous stationary test results show that capitalization rate LKSA and commercial value rate LTSA are both first-order co-integration. Besides, logarithmic capitalization rate LKSA and commercial value rate LTSA have both passed stationary test, hence satisfaction of the premises of co-integration test. Therefore Johannsen Co-integration Test is carried out and the result is shown in Table 2. 
Table 2. Johannsen Co-integration Test Result

\begin{tabular}{lccccc}
\hline \multicolumn{1}{c}{ Null hypothesis } & Eigenvalue & $\mathrm{t}$ statistic & $\begin{array}{c}\text { 5\% level of } \\
\text { significance }\end{array}$ & $\begin{array}{c}\text { Eigenvalue } \\
\text { of maximum }\end{array}$ & $\begin{array}{c}5 \% \text { level of } \\
\text { significance }\end{array}$ \\
\hline $\begin{array}{l}\text { No co-intergration } \\
\text { relationship** }\end{array}$ & 0.8293 & 133.2394 & 47.85613 & 102.5353 & 27.58434 \\
At most one* & 0.249128 & 30.70408 & 29.79707 & 16.61817 & 21.13162 \\
At most two & 0.178048 & 14.08591 & 15.49471 & 11.37228 & 14.2646 \\
At most three & 0.045709 & 2.713629 & 3.841466 & 2.713629 & 3.841466 \\
\hline
\end{tabular}

Johannsen Co-integration Test shows in Table 2 that on the 5\% level of significance, at least one co-integration relationship exists, namely there is a long term integration among economic growth rate LYSA, capitalization rate LKSA, commercial value rate LTSA and turnover rate LHSA. The adopted standardization co-integration equation is as follows (the number in the bracket refers to the statistics of $\mathrm{t}$ ):

$$
\text { LYSA }=\text {-78.24LKSA + 78.47LTSA - 78.05LHSA }
$$

Formula (1) shows that a long term balance relationship is actually a positive cointegration relationship between stock market commercial rate LTSA and economic growth rate LYSA, indicating a significant positive catalytic impact of transaction scale on economic growth. However, a negative co-integration relationship appears between economic growth and capitalization rate LKSA as well as turnover rate, which suggests that the current China stock market is still affected by many factors.

2.3.3. Granger Causality Test: Taking account of anticipated s mean square error (MSE) on $y_{\mathrm{t}}$ :

$$
\begin{aligned}
M S E=\frac{1}{s} \sum_{i=1}^{s}\left(\hat{y}_{t+i}-y_{t+i}\right)^{2}, & \operatorname{MSE}\left[\hat{E}\left(y_{t+s} \mid y_{t}, y_{t-1}, \cdots\right)\right] \\
= & \operatorname{MSE}\left[\hat{E}\left(y_{t+s} \mid y_{t}, y_{t-1}, \cdots, x_{t}, x_{t-1}, \cdots\right)\right]
\end{aligned}
$$

The conclusion can be drawn: $x$ cannot Granger cause $y$, equivalently, if the above formula is correct, we say $x$ is exogenous to $y$. Here is a third expression: $x$ has no linear effect information on future $y$.

The Granger causality in $\operatorname{VAR}(p)$ model resembles that of tow variables, by which we can judge where there is past influence. In a binary $p$ order,

$$
\left(\begin{array}{c}
y_{t} \\
x_{t}
\end{array}\right)=\left(\begin{array}{l}
\phi_{10} \\
\phi_{20}
\end{array}\right)+\left(\begin{array}{c}
\phi_{11}^{(1)} \phi_{12}^{(1)} \\
\phi_{21}^{(1)} \phi_{22}^{(1)}
\end{array}\right)\left(\begin{array}{c}
y_{t-1} \\
x_{t-1}
\end{array}\right)+\left(\begin{array}{l}
\phi_{11}^{(2)} \phi_{12}^{(2)} \\
\phi_{21}^{(2)} \phi_{22}^{(2)}
\end{array}\right)\left(\begin{array}{c}
y_{t-2} \\
x_{t-2}
\end{array}\right)+\cdots+\left(\begin{array}{l}
\phi_{11}^{(p)} \phi_{12}^{(p)} \\
\phi_{21}^{(p)} \phi_{22}^{(p)}
\end{array}\right)\left(\begin{array}{l}
y_{1-p} \\
x_{1-p}
\end{array}\right)+\left(\begin{array}{l}
\varepsilon_{1 t} \\
\varepsilon_{2 t}
\end{array}\right)
$$

We can see from the above Johansen Co-integration test a long term balanced relationship between economic growth and stock market, but Granger causality test is still necessary. The result of Granger causality is shown in Table 3. 
Table 3. Granger Causality Test Result on Variables

\begin{tabular}{ccccc}
\hline Null hypothesis & $\begin{array}{l}\text { Lag intervals } \\
\text { for } \\
\text { endogenous }\end{array}$ & F statistics & P value & Conclusion \\
\hline LKSA is not Granger cause LYSA & 7 & 2.69896 & 0.0195 & refuse \\
LYSA is not Granger cause LKSA & 7 & 2.04166 & 0.06892 & accept \\
LTSA is not Granger cause LYSA & 7 & 1.64167 & 0.14742 & accept \\
LYSA is not Granger cause LTSA & 7 & 0.25722 & 0.97558 & accept \\
LHSA is not Granger cause LYSA & 7 & 1.0593 & 0.41231 & accept \\
LYSA is not Granger cause LHSA & 7 & 0.78925 & 0.61529 & accept \\
LTSA is not Granger cause LKSA & 7 & 3.87941 & 0.0022 & refuse \\
LKSA is not Granger cause LTSA & 7 & 2.27206 & 0.04424 & refuse \\
LHSA is not Granger cause LKSA & 7 & 3.21779 & 0.00733 & refuse \\
LKSA is not Granger cause LHSA & 7 & 1.98617 & 0.07666 & accept \\
LHSA is not Granger cause LTSA & 7 & 1.38185 & 0.23749 & accept \\
LTSA is not Granger cause LHSA & 7 & 1.62821 & 0.15118 & accept \\
\hline
\end{tabular}

2.3.4. Build Model: The mathematical expression of $\operatorname{VAR}(p)$ is:

$$
\mathbf{y}_{t}=\boldsymbol{\Phi}_{1} \mathbf{y}_{t-1}+\cdots+\boldsymbol{\Phi}_{p} \mathbf{y}_{t-p}+\mathbf{H} \mathbf{x}_{t}+\boldsymbol{\varepsilon}_{t}
$$

$t=1,2, \cdots, T$. In the formula, $y_{\mathrm{t}}$ refers to $\mathrm{k}$ dimension endogenous variable column vector, $x_{\mathrm{t}}$ refers to d dimension exogenous variable column vector, $\mathrm{p}$ refers to lag order and $T$ refers to individual sample. $k \times k$ dimension matrix $\Phi_{1}, \ldots, \Phi_{p}$ and $k \times d$ matrix $\mathrm{H}$ refer to the coefficient matrix to be estimated. $\varepsilon_{\mathrm{t}}$ is disturbance column vector, supposing $\sum$ is the covariance matrix of $\varepsilon_{\mathrm{t}}$, a $(k \times k)$ positive definite matrix. Formula (1) can be unfolded like:

$$
\left(\begin{array}{c}
y_{1 t} \\
y_{2 t} \\
\vdots \\
y_{k t}
\end{array}\right)=\boldsymbol{\Phi}_{1}\left(\begin{array}{c}
y_{1 t-1} \\
y_{2 t-1} \\
\vdots \\
y_{k t-1}
\end{array}\right)+\cdots+\boldsymbol{\Phi}_{p}\left(\begin{array}{c}
y_{1 t-p} \\
y_{2 t-p} \\
\vdots \\
y_{k t-p}
\end{array}\right)+\mathbf{H}\left(\begin{array}{c}
x_{1 t} \\
x_{2 t} \\
\vdots \\
x_{d t}
\end{array}\right)+\left(\begin{array}{c}
\varepsilon_{1 t} \\
\varepsilon_{2 t} \\
\vdots \\
\varepsilon_{k t}
\end{array}\right)
$$

Formula (5) is generally referred to as an unrestricted vector autoregression model. Strike vector $\varepsilon_{\mathrm{t}}$ means white noise vector. The considered VAR models in the following are all unrestricted vector autoregression models, expressed by formula below:

$$
y_{t}=\Phi_{1} y_{t-1}+\cdots+\Phi_{p} y_{1-p}+\varepsilon_{1} \text { or } \Phi(L) y_{t}=\varepsilon_{t}
$$

The relation among LYSA, LKSA and TSA will be examined by VAR model.

Table 4. General Effect Test of Model VAR (3)

\begin{tabular}{ll} 
Determinant resid covariance & $7.07 \mathrm{E}-09$ \\
Log likelihood & 600.0826 \\
Akaike information criterion & -9.745001 \\
Schwarz criterion & -9.036752 \\
\hline
\end{tabular}


Table 5. General Effect Test of Model VAR (2)

\begin{tabular}{lc} 
Determinant resid covariance & $8.70 \mathrm{E}-08$ \\
Log likelihood & 592.7248 \\
Akaike information criterion & -9.693401 \\
Schwarz criterion & -9.145354 \\
\hline
\end{tabular}

We can see from Table 4 and Table 5 that the minimum AIC appears when the maximum lag phrase is 3 , while the minimum SC appears when the lag phrase is 2, therefore it is hard to determine. In response, LYSA test is adopted to make the choice. The maximum lag phrase of the model is originally assumed to be 2 . Test statistics $\mathrm{LYSA}={ }^{-2 \times\left(l_{2}-l_{3}\right)}={ }^{-2 *(592.7248-600.0826)}=14.7156$, of which $l_{2}$ and $l_{3}$ respectively refer to the $\log$ likehood when $\rho=2$ and $\rho=3$. Under null hypothesis, the statistics contain progressive $\chi^{2}$ distribution, of which the degree of freedom is the number of zero restrictions imposed on the model parameter from VAR(3) to $\operatorname{VAR}(2)$. The concomitance probability tested by the program is 0.009 , which agrees with the original hypothesis, that is to say, 2 is adopted for the lag phrase. VAR model without constraint condition of the 2 lag phrase will be established:

Table 6. Fitting Result of Model VAR (2)

\begin{tabular}{|c|c|c|c|}
\hline & LKSA & LTSA & LYSA \\
\hline \multirow{3}{*}{ LKSA (-1) } & 1.024213 & -0.022319 & -0.011487 \\
\hline & $(0.09539)$ & (0.03369) & $(0.04519)$ \\
\hline & [10.7373] & {$[-0.66252]$} & {$[-0.25421]$} \\
\hline \multirow{3}{*}{ LKSA $(-2)$} & 0.005809 & 0.015769 & 0.062536 \\
\hline & $(0.10180)$ & $(0.03595)$ & $(0.04822)$ \\
\hline & {$[0.05706]$} & [0.43860] & [1.29680] \\
\hline \multirow{3}{*}{ LTSA $(-1)$} & 0.062487 & 0.797601 & -0.058413 \\
\hline & $(0.20134)$ & $(0.07111)$ & $(0.09537)$ \\
\hline & [0.31035] & [11.2179] & {$[-0.61246]$} \\
\hline \multirow{3}{*}{ LTSA $(-2)$} & -0.015846 & 0.191106 & 0.063525 \\
\hline & $(0.19828)$ & $(0.07003)$ & $(0.09329)$ \\
\hline & {$[-0.07999]$} & [2.72909] & [0.67643] \\
\hline \multirow{3}{*}{ LYSA (-1) } & -0.168172 & 0.683533 & 1.243445 \\
\hline & $(0.19252)$ & $(0.06799)$ & $(0.09120)$ \\
\hline & {$[-0.87352]$} & [-9.85524] & [13.6346] \\
\hline \multirow{6}{*}{ LYSA (-2) } & -0.10182 & -0.649903 & -0.345272 \\
\hline & $(0.18672)$ & $(0.06594)$ & $(0.08845)$ \\
\hline & {$[-0.05453]$} & {$[-9.85524]$} & {$[-3.90354]$} \\
\hline & -0.646474 & 0.174765 & -0.359647 \\
\hline & $(0.33193)$ & $(0.11723)$ & $(0.15724)$ \\
\hline & {$[-1.94761]$} & [1.49081] & {$[-2.28729]$} \\
\hline R-squared & 0.958048 & 0.996051 & 0.969278 \\
\hline Adj.R-squared & 0.955780 & 0.995838 & 0.967617 \\
\hline Sum.sq.resids & 0.811305 & 0.101193 & 0.182051 \\
\hline S.E.equation & 0.085493 & 0.030194 & 0.040498 \\
\hline F-statistic & 422.4817 & 4666.642 & 583.6758 \\
\hline Log likelihood & 126.3732 & 249.1885 & 214.5402 \\
\hline Akaike AIC & -2.023274 & -4.104889 & -3.517631 \\
\hline Schwarz SC & -1.858912 & -3.940527 & -3.353268 \\
\hline Mean dependent & 7.569030 & 12.46523 & 0.874152 \\
\hline S.D.dependent & 0.406559 & 0.468013 & 0.225050 \\
\hline
\end{tabular}




\subsection{Empirical Analysis}

The empirical analysis shows: a one-way Granger causality exists between the capitalization rate LKSA of stock market development scale and the economic growth rate LYSA of GDP growth; some causality exists between the turnover rate LHSA of stock market transaction animation and the capitalization rate LKSA of the stack market development scale; a two-way causality exists between the capitalization rate LKSA of stock market development scale and the commercial value rate LTSA economic aggregate.

\section{Conclusions}

The empirical analysis of stock market and economic growth shows: a one-way Granger causality exists between the capitalization rate LKSA of stock market development scale and the economic growth rate LYSA of GDP growth, which indicates that the development scale of stock market is the one-way Granger causality to economic growth, that is to say, a well developed stock market will push forward economic development and a listed company may raise capitals by issuing stocks on the stock market; some causality exists between the turnover rate LHSA of stock market transaction animation and the capitalization rate LKSA of the stack market development scale, which indicates that stock market animation is the one-way Granger causality to stock market development scale, which gathers more capitals for the issuance of stocks, hence a constant promoter to the stock market development scale; a two-way causality exists between the capitalization rate LKSA of stock market development scale and the commercial value rate LTSA economic aggregate, which indicates that the capitalization rate of stocks and the commercial value rate of stock market can promote each other, that is to say, the better the stock market develops, with rise of stock prices, the higher the value of stocks.

\section{Acknowledgements}

This research was supported by the Department of Education of Heilongiiang Province under Grant No..12532083, Grant No 12521148 and the Harbin University of Commerce Natural Science Foundation of Young Teachers under Grant No HCUL2013012.

\section{References}

[1] J. M. Alnold, Ivo, "Fundamental uncertainty and stock market volatility", Applied Financial Economics, vol.18, no. 17, (2008), pp.1425-1440

[2] S. Ahn, Eun, "Volatility relationship between stock performance and real output", Applied Financial Economics, (2006), vol. 16, pp.777-784.

[3] I. Roger, "Stock Market Returns in the Long Run", Yale School of Management, (2002).

[4] H.B. Duan, G. Yang, "Stock Market Development and Economic Growth: Evidence of China", Journal of Central University of Finance \& Economics, (2009), vol. 12, pp. 31-36.

[5] W.B. Luo, "Stock market development, financial domains of economic growth: theoretical analysis and empirical research based on capital formation and the optimal size of the financial perspective", East China Normal University, (2010).

[6] C. Z. Wei, K. Sun, S. M. Yang, "An empirical study on the relationship between stock market and economic growth", Technology and market, vol. 19, , (2012), pp. 129-131.

[7] L. Xie, X. W. Lu, "Relativity between China stock market and economic growth based on VAR", Technology and Innovation Management, vol.4, (2012), pp.409-413. 
International Journal of $u-$ and e- Service, Science and Technology Vol.8, No.5 (2015) 